\title{
Phenoxodiol Increases Cisplatin Sensitivity in Ovarian Clear Cancer Cells Through XIAP Down-regulation and Autophagy Inhibition
}

\author{
MORIKAZU MIYAMOTO ${ }^{1}$, MASASHI TAKANO ${ }^{2}$, TADASHI AOYAMA ${ }^{1}$, HIROAKI SOYAMA $^{1}$, \\ HIROKI ISHIBASHI ${ }^{1}$, KENTO KATO $^{1}$, HIDEKI IWAHASHI ${ }^{1}$, KAZUKI TAKASAKI ${ }^{1}$, MIKA KUWAHARA ${ }^{1}$, \\ HIROKO MATUURA ${ }^{1}$, TAKAHIRO SAKAMOTO ${ }^{1}$, TOMOYUKI YOSHIKAWA ${ }^{2}$ and KENICHI FURUYA ${ }^{1}$ \\ Departments of ${ }^{1}$ Obstetrics and Gynecology and ${ }^{2}$ Clinical Oncology, \\ National Defense Medical College Hospital, Tokorozawa, Japan
}

\begin{abstract}
Background/Aim: To investigate whether XIAP down-regulation and autophagy inhibition sensitize ovarian clear cell cancer cells to cisplatin. Materials and Methods: The ovarian clear cancer cell line $K K$ was used for in vitro analysis. Hydroxychloroquine (HCQ) and phenoxodiol (PXD) or embelin were used as autophagy and XIAP inhibitors, respectively. Nonspecific and XIAP-specific siRNAs were transfected using Lipofectamine. Cytotoxicity was assessed by MTT assays. Protein expression was confirmed by western blotting. Results: In KK, down-regulation of XIAP using specific siRNAs together with $H C Q$ treatment enhanced the anti-tumor effect of cisplatin. Although embelin sensitized KK to cisplatin through XIAP down-regulation, it induced autophagy. However, PXD increased cisplatin sensitivity through XIAP down-regulation and autophagy inhibition. Expression of Atg7, Atg12, and Beclin 1 was decreased after PXD treatment. Conclusion: PXD increased cisplatin sensitivity through XIAP down-regulation and autophagy inhibition and could be a new candidate for ovarian clear cell carcinoma treatment.
\end{abstract}

Ovarian carcinoma is a major cause of deaths among gynecological malignancies. Incidence of mortality due to epithelial ovarian carcinoma (EOC) has been increasing. The prognosis of patients in the advanced stage is poor despite advances in chemotherapy $(1,2)$. Among the histological subtypes, treatment for ovarian clear cell carcinomas (CCC)

Correspondence to: Morikazu Miyamoto, Department of Obstetrics and Gynecology1, National Defense Medical College Hospital, Tokorozawa, Saitama, 359-8513, Japan. Tel: +81 429951687, e-mail: morikazu1118@hotmail.co.jp

Key Words: Ovarian clear cell carcinoma, X-chromosome-linked inhibitor of apoptosis (XIAP), autophagy, phenoxodiol, platinum resistance. is difficult because of its extremely low response rate to platinum-based chemotherapy compared with that of the more prevalent ovarian serous carcinomas (3-5). This characteristic of CCC is one of the factors of treatment failure and is a problem that needs to be solved urgently.

The X-chromosome-linked inhibitor of apoptosis (XIAP) protein is one of the inhibitors of caspases and apoptosis (6). XIAP is one of the factors of platinum resistance in ovarian serous cancer cells as well as CCC $(7,8)$. Thus, XIAP could be a potential therapeutic target in CCC and serous subtypes of ovarian cancer. The phase III OVATURE multicenter randomized study demonstrated no evidence of clinical activity against acquired platinum-resistant ovarian cancer with the combination of a XIAP inhibitor (Phenoxodiol: PXD) and carboplatin (9). However, this study did not include CCC in the PXD arm and the anti-tumor activity of PXD in CCC has not been clarified. In addition, embelin, another XIAP inhibitor, has shown anti-cancer activity in experimental models of several cancers (10-13), but experiments targeting ovarian CCCs have not been reported.

On the other hand, high expression of the autophagy protein LC3A correlated with prognosis of patient survival in CCC. Ovarian CCC cell lines underwent apoptosis upon inhibition of autophagy with hydroxychloroquine (HCQ) $(14,15)$, which suggests that autophagy might be a new therapeutic target in ovarian CCCs. Recently, XIAP protein was reported as one of the regulators of autophagy $(16,17)$. In brief, down-regulation of XIAP using siRNA and embelin was found to increase autophagy (16); conversely, XIAP gene amplification induced autophagy (17). These results suggest that XIAP regulates autophagy inhibition and activation. The association between the regulation of both XIAP protein and autophagy, and cisplatin sensitivity in ovarian CCC is not known.

Herein, our study investigated the association between XIAP-regulated autophagy and cisplatin sensitivity in ovarian CCC cells and determined whether PXD and 
embelin demonstrate anti-tumor activity in ovarian clear cell cancer, through in vitro analysis.

\section{Materials and Methods}

Reagents/antibodies. HCQ was purchased from Abcam, Cambridge, UK. Embelin was purchased from Calbiochem, San Diego, CA, USA. Cisplatin was purchased from Bristol Meier's Squib Oncology, Tokyo, Japan. PXD was purchased from Sigma-Aldrich, Tokyo, Japan. Primary antibodies against XIAP, PARP, cleaved PARP, LC3A, and $\beta$ actin, secondary antibodies, and XIAP specific and control siRNAs were obtained from Cell Signaling Technology, Beverly, MA, USA.

Cell lines and culture conditions. The ovarian CCC cell line KK (18) was used for all experiments. These cells were grown as monolayer cultures in RPMI-1640+GlutmaxTM-I (Invitrogen Japan KK, Tokyo, Japan) medium supplemented with $10 \%$ fetal bovine serum (Invitrogen Japan KK, Tokyo, Japan), $100 \mathrm{U}$ penicillin per $\mathrm{ml}$, and $100 \mathrm{mg}$ streptomycin per $\mathrm{ml}$ (Invitrogen, Tokyo, Japan KK) in a humidified atmosphere with $5 \% \mathrm{CO}_{2}$ at $37^{\circ} \mathrm{C}$, and were routinely tested for mycoplasma infection. Protein concentrations were determined using a Bradford assay (Bio-Rad Laboratories, Hercules, CA, USA).

Transient transfection. KK cells cultured in $3.5-\mathrm{cm}$ plates were transfected with $107 \mathrm{nM}$ of XIAP siRNA and control siRNA, using Lipofectamine 2000 (Invitrogen, Tokyo, Japan KK) according to the manufacturer's specifications. Knockdown of XIAP was confirmed by western blot analysis in all experiments.

Cell proliferation and cytotoxicity assays. KK cells were seeded onto 96-well plates at approximately $1 \times 10^{4}$ or $4 \times 10^{4}$ cells $\mathrm{cm}^{-2}$ for the cytotoxicity assays. Cell viability was determined by the MTT method using Tetra Color ONE (Seikagaku Corporation, Tokyo, Japan) according to the manufacturer's instructions. Cytotoxicity by PXD, embelin, and HCQ was measured after 5 days of treatment at different concentrations. To determine the effect of cisplatin after pretreatment with PXD, embelin, and HCQ, or siRNA transfection, KK cells were treated with several reagents at different concentrations for 24 hours. Cisplatin was then added to KK cells at different doses, and cell survival was measured after 5 days of cisplatin treatment.

Preparation of cell lysates for western blot analysis. Protein lysates were extracted in RIPA buffer ${ }^{\circledR}$ according to the manufacturer's instructions (Wako Pure Chemical Industries, Ltd. Osaka, Japan). Cytosolic fractions were prepared $(10 \mu \mathrm{g})$ and loaded onto a MiniPROTEIN $^{\circledR}$ TGX $^{\mathrm{TM}}$ gel (Bio-Rad Laboratories, Hercules, CA, USA). After electrophoresis, proteins were transferred to PVDF membranes using the Trans-Blot ${ }^{\circledR}$ Turbo $^{\mathrm{TM}}$ Transfer System Transfer Pack (Bio-Rad Laboratories, Hercules, CA, USA). Subsequently, the membranes were blocked for 1 hour with $4 \%$ BSA in TBS with $0.5 \%$ Tween-20 (TBS-T) and incubated overnight at $4{ }^{\circ} \mathrm{C}$ with the primary antibody in TBS-T containing $4 \%$ BSA. The following antibodies and concentrations were used: 1/2,500 rabbit anti-XIAP, 1/2,500 rabbit LC3A, 1/2,500 rabbit cleaved PARP, 1/2,500 rabbit PARP, 1/2,500 rabbit Atg7, 1/2,500 rabbit Atg12, $1 / 2,500$ rabbit Beclin-1, and 1/5,000 rabbit $\beta$-actin. After three washes with TBS-T, the membranes were incubated for 1 hour at room temperature with horseradish peroxidase-conjugated antirabbit secondary antibody as appropriate. After three washes with TBS-T, the blots were visualized using an ECL detection system
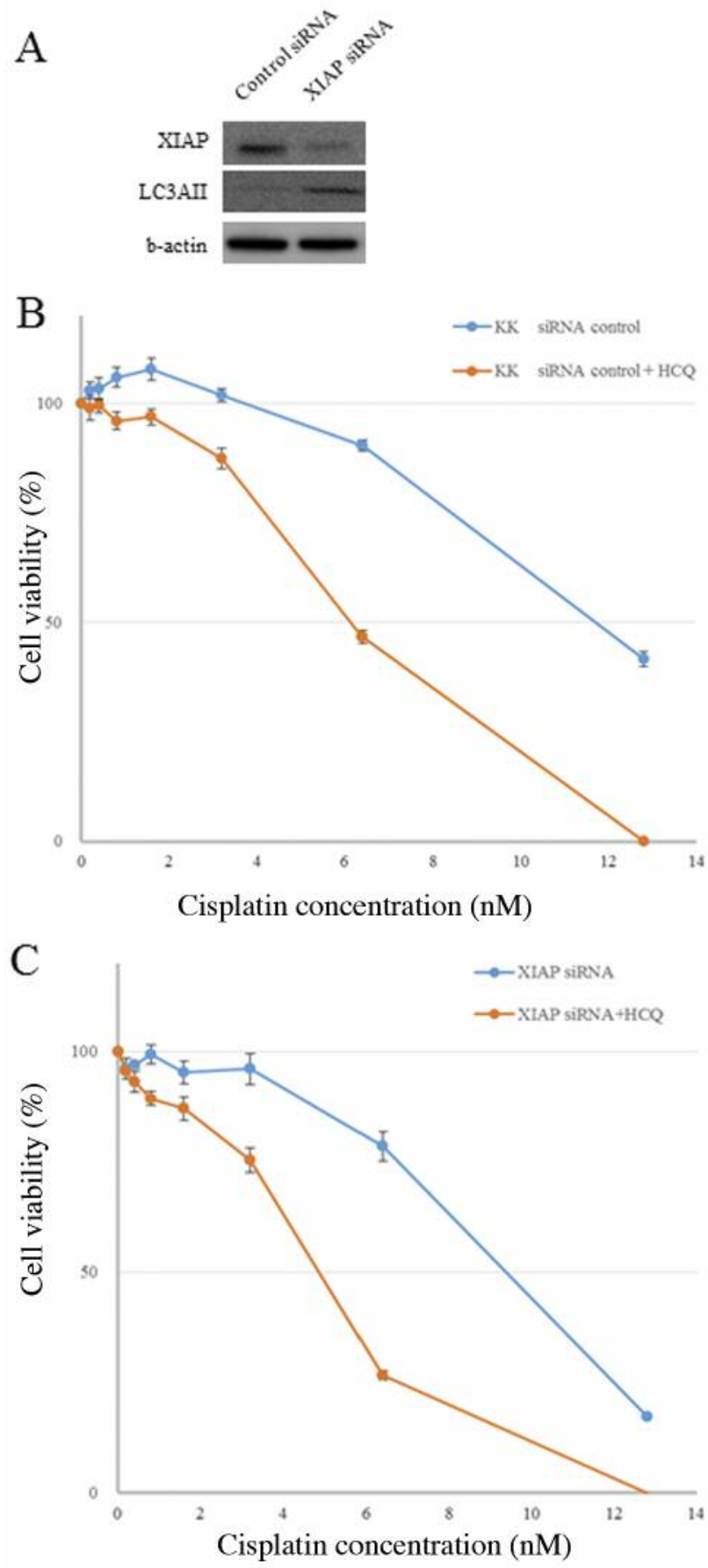

Figure 1. Hydroxychloroquine (HCQ) treatment after transfection with either control or XIAP siRNA increased cisplatin sensitivity in ovarian clear cell cancer cells. After transfection with control siRNA and XIAP siRNA, western blot analysis revealed XIAP down-regulation and LC $3 A$ II up-regulation in KK cells (A).KK cells transfected with control siRNA or XIAP siRNA were treated with HCQ. Cisplatin sensitivity was increased in KK cells transfected with either control $(B)$ or XIAPspecific siRNAs $(C)$. Equivalent amounts $(10 \mu \mathrm{g})$ of protein were subjected to SDS-PAGE and blotted with anti-XIAP and anti-LC3A antibodies. Cell viability was assessed at 5 days after treatment by an MTT assay. The data represent at least three independent experiments. 

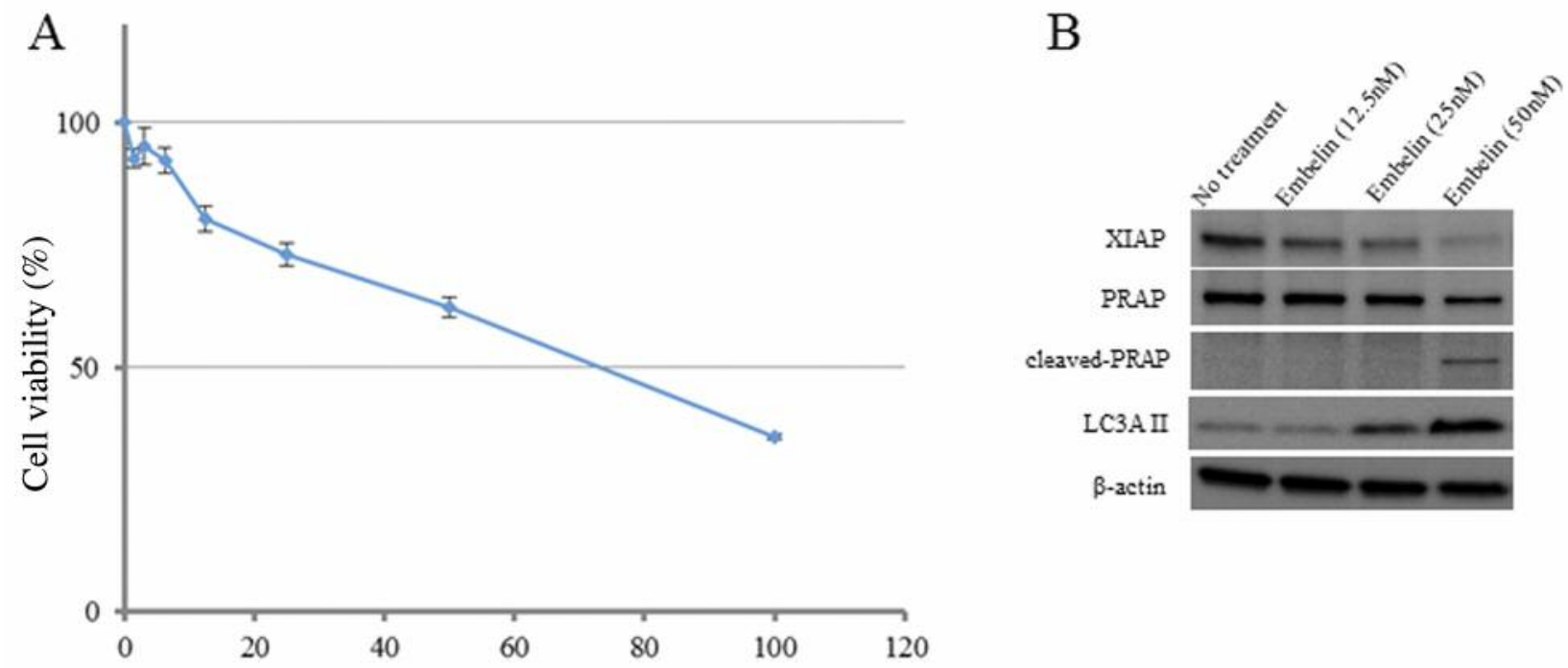

Embelin concentration (nM)
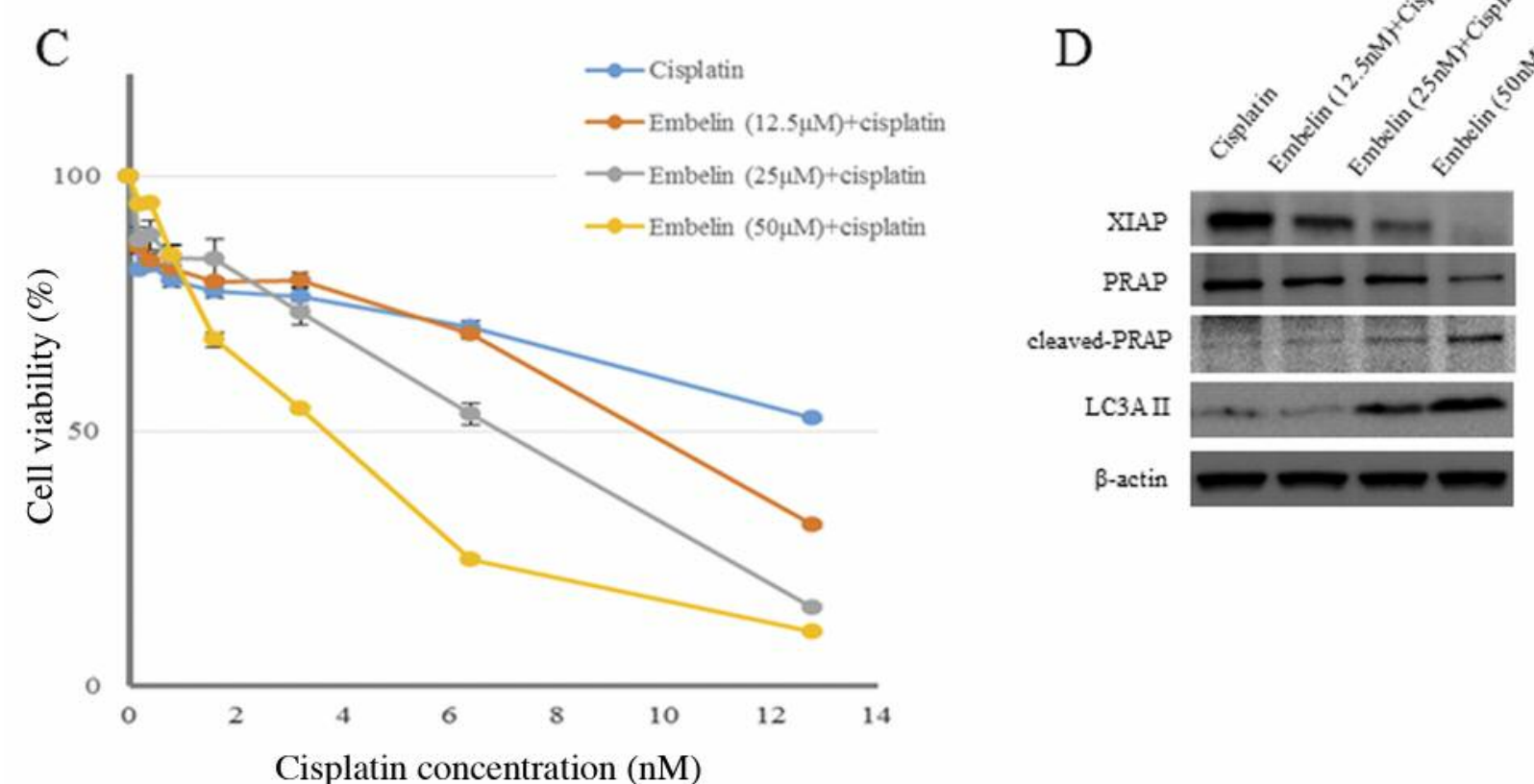

Figure 2. Embelin increased cisplatin sensitivity in the ovarian clear cell cancer cell line, KK. Embelin showed an anti-tumor effect on KK as a single agent, through down-regulation of XIAP but not LC3A II (A, B). Embelin sensitized KK cells to cisplatin at different concentrations $(C)$. Similarly, the combination of embelin and cisplatin induced down-regulation of XIAP but not LC3A. Equivalent amounts (10 $\mu \mathrm{g})$ of protein were subjected to SDS-PAGE and blotted with anti-XIAP, anti-PARP, anti-cleaved PARP, anti LC3A, and anti- $\beta$-actin antibodies. Cell viability was assessed by an MTT assay. The data represent at least three independent experiments.

(GE Healthcare UK Ltd, England, UK) on a LAS-3000 (Fujifilm, Minato, Tokyo, Japan). Protein expression was determined densitometrically and normalized against $\beta$-actin expression using Multi Gauge version 3.1 (FujiFilm, Tokyo, Japan).

Statistical analysis. The Stat View software ver.5.0 (SAS Institution Inc., NC, USA) was used for statistical analysis. All experiments were repeated independently at least three times. All values are presented as mean \pm s.d. Statistical significance between two groups was determined by a two-tailed $t$-test or ANOVA. Statistical significance was defined at $p<0.05$.

\section{Results}

Transfection with XIAP-specific siRNA induced downregulation of XIAP and up-regulation of LC3A II (Figure 

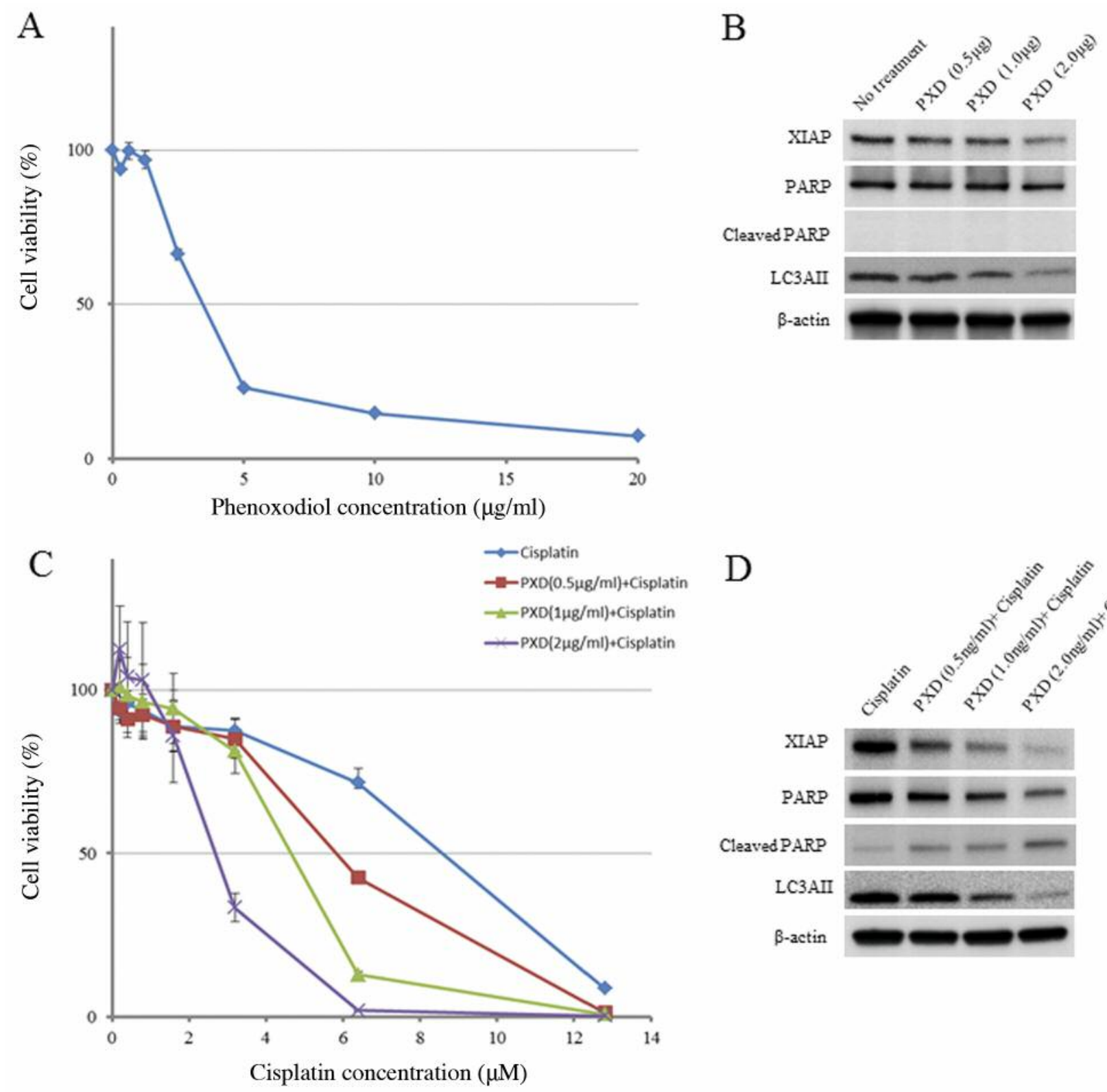

Figure 3. Phenoxodiol (PXD) sensitized ovarian clear cell carcinoma cells KK through XIAP down-regulation and autophagy inhibition. (A) The antitumor activity of PXD as a single agent was determined. (B) Downregulation of XIAP and LC3AII protein was observed after PXD treatment for 24 h. (C) Pre-treatment with PXD increased the sensitivity of KK to cisplatin in a dose-dependent manner. (D) In addition to XIAP and LC3A II protein down-regulation, cleaved PARP was up-regulated after treatment with $10 \mathrm{nM}$ of cisplatin in KK cells pre-treated with PXD. Equivalent amounts $(10 \mu \mathrm{g})$ of protein were subjected to SDS-PAGE and blotted with anti-XIAP, anti-PARP, anti-cleaved PARP, anti-LC3A, and anti- $\beta$-actin antibodies. Cell viability was assessed at 5 days after treatment by an MTT assay. The data represent at least three independent experiments.

1A). After treatment with $25 \mu \mathrm{M}$ of HCQ for $24 \mathrm{~h}$ in KK cells transfected with either control or XIAP-specific siRNA, an assay for cisplatin cytotoxicity was conducted. HCQ increased the cisplatin sensitivity in both transfected cells (Figure 1B and C). Thus, XIAP down-regulation and autophagy blockade sensitized ovarian CCC cells to cisplatin.
Embelin as a single agent showed anti-tumor activity (Figure 2A). After embelin treatment for $24 \mathrm{~h}$ at doses of $12.5 \mu \mathrm{M}, 25 \mu \mathrm{M}$, and $50 \mu \mathrm{M}$, XIAP protein levels were decreased but LC3A II protein levels increased (Figure 2B). Pre-treatment with embelin for $24 \mathrm{~h}$ at several doses increased the sensitivity of KK cells to cisplatin (Figure 2C). 


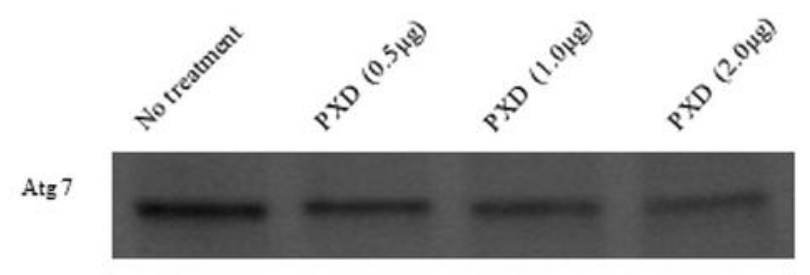

Atg 12

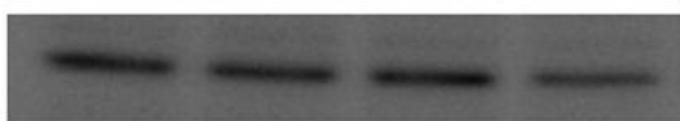

Beclin 1

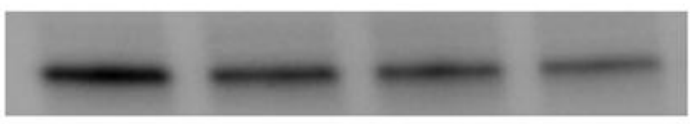

B-actin

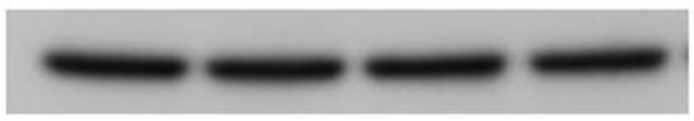

Figure 4. The cascade of autophagy blockade in KK cells treated with phenoxodiol. Cell lysates were prepared after treatment with phenoxodiol for $24 \mathrm{~h}$. Equivalent amounts $(10 \mu \mathrm{g})$ of protein were subjected to SDS-PAGE and blotted with anti-Atg7, anti-Atg12, antiBeclin-1, and anti- $\beta$-actin antibodies. Atg7, Atg12, and Beclin1 protein levels were found to be downregulated. The data represent at least three independent experiments.

After embelin treatment at several doses for $24 \mathrm{~h}$ followed by cisplatin treatment for 24 hours at a dose of $10 \mu \mathrm{M}$, XIAP protein levels decreased and both cleaved-PARP and LC3A II protein levels were increased (Figure 2D). Thus, embelin increased sensitivity to cisplatin through down-regulation XIAP and induction of autophagy.

PXD showed anti-tumor activity as a single agent (Figure 3A). After PXD treatment for $24 \mathrm{~h}$ at a dose of $0.5 \mu \mathrm{g} / \mathrm{ml}, 1.0$ $\mu \mathrm{g} / \mathrm{ml}$, and $2.0 \mu \mathrm{g} / \mathrm{ml}$, XIAP and LC3A II protein levels were decreased (Figure 3B). Pre-treatment with PXD at several doses for 24 hours increased the sensitivity of KK cells to cisplatin (Figure 3C). After PXD treatment at several doses for $24 \mathrm{~h}$ followed by cisplatin treatment at a dose of $10 \mu \mathrm{M}$ for $24 \mathrm{~h}$, XIAP and LC3A II protein levels were found to be decreased, whereas cleaved-PARP protein levels were increased (Figure 3D). Thus, PXD increased cisplatin sensitivity through down-regulation of XIAP and autophagy blockade. After PXD treatment for $24 \mathrm{~h}$, western blot analysis was performed and Atg7, Atg12, and Beclin-1 protein levels were found to be down-regulated (Figure 4).

\section{Discussion}

XIAP protein regulates the induction and inhibition of autophagy $(16,17)$. Autophagy activation was associated with poor prognosis in CCC and inhibition of autophagy was found to induce apoptosis in ovarian CCC cell lines $(14,15)$.
In our study, XIAP down-regulation using siRNA induced activation of autophagy. Even in this condition, XIAP protein down-regulation enhanced cisplatin sensitivity in KK cells. Furthermore, HCQ treatment in addition to XIAP downregulation increased the sensitivity of ovarian CCC cells to cisplatin more effectively. Embelin demonstrated an antitumor effect as a single agent and enhanced cisplatin sensitivity but also activated autophagy. Conversely, PXD increased the sensitivity to cisplatin through XIAP downregulation as well as inhibition of autophagy. PXD-induced XIAP down-regulation inhibited autophagy through Beclin1. Although it was unclear whether PXD and embelin possess clinical activity, PXD might be more suitable for treating $\mathrm{CCC}$ considering the underlying mechanism.

PXD, an isoflavone derivative, has demonstrated antitumor effects in several human cancer cell lines, including ovarian serous cancer cell lines (19). PXD caused apoptosis in cancer cells by downregulating XIAP, as well as by disrupting FLICE inhibitory protein (FLIP) expression (20), anti-angiogenesis activity (20), causing cell cycle arrest at G1 (21), inhibiting topoisomerase II (22), and upregulating Bax (23). In addition to these effects, the present study demonstrates that PXD inhibits autophagy. Previous studies have demonstrated XIAP protein (8), autophagy $(14,15)$, and anti-angiogenesis (24) as candidates of future targeted therapies against CCC. PXD inhibits these factors as a single agent. Therefore, future studies could confirm whether PXD shows clinical activity in CCC treatment.

XIAP-targeted therapy might be a promising treatment for CCC. In colon cancer, PIK3CA-mutated colorectal cancer cells treated with XIAP-targeting drugs underwent receptorinduced apoptosis (25). As PIK3CA mutations are more frequently observed in CCC, at a frequency of $33 \%$ (26), it would be interesting to investigate the association between PIK3CA mutation and responses to XIAP inhibitors.

In conclusion, XIAP down-regulation and inhibition of autophagy increased cisplatin sensitivity in ovarian CCC cell lines. PXD sensitized ovarian CCC cell lines to cisplatin through down-regulation of XIAP and inhibition of autophagy.

\section{Conflicts of Interest}

The Authors declare no potential conflicts of interest.

\section{Acknowledgements}

None.

\section{References}

1 Young RC, Decker DG, Wharton JT, Piver MS, Sindelar WF, Edwards BK and Smith JP: Staging laparotomy in early ovarian cancer. JAMA 250: 3072-3076, 1983. 
2 Cannistra SA: Cancer of the ovary. N Engl J Med 351: 25192529, 2004.

3 Sugiyama T, Kamura T, Kigawa J, Terakawa N, Kikuchi Y, Kita T, Suzuki M, Sato I and Taguchi K: Clinical characteristics of clear cell carcinoma of the ovary. Cancer 88: 2584-2587, 2000.

4 Takano M, Kikuchi Y, Yaegashi N, Kuzuya K, Ueki M, Tsuda H, Suzuki M, Kigawa J, Takeuchi S, Tsuda H, Moriya T and Sugiyama T: Clear cell carcinoma of the ovary: a retrospective multicentre experience of 254 patients with complete surgical staging. Br J Cancer 94: 1369-1374, 2006.

5 Miyamoto M, Takano M, Goto T, Kato M, Sasaki N, Tsuda H and Furuya K: Clear cell histology as a poor prognostic factor for advanced epithelial ovarian cancer: a single institutional case series through central pathologic review. J Gynecol Oncol 24: 37-43, 2013.

6 Deveraux QL, Takahashi R, Salvesen GS and Reed JC: X-linked IAP is a direct inhibitor of cell-death proteases. Nature 388: 300304, 1997.

7 Cheng JQ, Jiang X, Fraser M, Li M, Dan HC, Sun M and Tsang BK: Role of X-linked inhibitor of apoptosis protein in chemoresistance in ovarian cancer: possible involvement of the phosphoinositide-3 kinase/Akt pathway. Drug Resist Updat 5: 131-146, 2002.

8 Miyamoto M, Takano M, Iwaya K, Shinomiya N, Kato M, Aoyama T, Sasaki N, Goto T, Suzuki A, Hirata J and Furuya K: $\mathrm{X}$-chromosome-linked inhibitor of apoptosis as a key factor for chemoresistance in clear cell carcinoma of the ovary. $\mathrm{Br} \mathrm{J}$ Cancer 110: 2881-2886, 2014.

9 Fotopoulou C, Vergote I, Mainwaring P, Bidzinski M, Vermorken JB, Ghamande SA, Harnett P, Del Prete SA, Green JA, Spaczynski M, Blagden S, Gore M, Ledermann J, Kaye S and Gabra H: Weekly AUC2 carboplatin in acquired platinumresistant ovarian cancer with or without oral phenoxodiol, a sensitizer of platinum cytotoxicity: the phase III OVATURE multicenter randomized study. Ann Oncol 25: 160-165, 2014.

10 Peng M, Huang B, Zhang Q, Fu S, Wang D, Cheng X, Wu X, Xue Z, Zhang L, Zhang D, Da Y, Dai Y, Yang Q, Yao Z, Qiao L and Zhang R: Embelin inhibits pancreatic cancer progression by directly inducing cancer cell apoptosis and indirectly restricting IL-6 associated inflammatory and immune suppressive cells. Cancer Lett 354: 407-416, 2014.

11 Moreno-Martínez D, Nomdedeu M, Lara-Castillo MC, Etxabe A, Pratcorona M, Tesi N, Díaz-Beyá M, Rozman M, Montserrat E, Urbano-Ispizua A, Esteve J and Risueño RM: XIAP inhibitors induce differentiation and impair clonogenic capacity of acute myeloid leukemia stem cells. Oncotarget 5: 4337-4346, 2014.

12 Park N, Baek HS and Chun YJ: Embelin-induced apoptosis of human prostate cancer cells is mediated through modulation of Akt and $\beta$-Catenin signaling. PLoS One 10: e0134760, 2015.

13 Nigam N, Grover A, Goyal S, Katiyar SP, Bhargava P, Wang PC, Sundar D, Kaul SC and Wadhwa R: Targeting mortalin by embelin causes activation of tumor suppressor p53 and deactivation of metastatic signaling in human breast cancer cells. PLoS One 10: e0138192, 2015.

14 Spowart JE, Townsend KN, Huwait H, Eshragh S, West NR, Ries JN, Kalloger S, Anglesio M, Gorski SM, Watson PH, Gilks CB, Huntsman DG and Lum JJ: The autophagy protein LC3A correlates with hypoxia and is a prognostic marker of patient survival in clear cell ovarian cancer. J Pathol 228: 437-447, 2012.
15 Miyamoto M, Takano M, Aoyama T, Soyama H, Yoshikawa T, Tsuda $\mathrm{H}$ and Furuya K: Inhibition of autophagy protein LC3A as a therapeutic target in ovarian clear cell carcinomas. J Gynecol Oncol 28: e33, 2017.

16 Huang X, Wu Z, Mei Y and Wu M: XIAP inhibits autophagy via XIAP-Mdm2-p53 signalling. EMBO J 32: 2204-2216, 2013.

17 Lin F, Ghislat G, Luo S, Renna M, Siddiqi F and Rubinsztein DC: XIAP and cIAP1 amplifications induce Beclin 1-dependent autophagy through NFKB activation. Hum Mol Genet 24: 28992913, 2015

18 Sasa H, Ishii K, Hirata J, Kikuchi Y, Nagata I, Kawai T, Senoo A, Sugita M, Sugishita T and Tenjin Y: Establishment and characterization of a CA-125-producing human ovarian clear cell carcinoma cell line. Hum Cell 6: 279-286, 1993.

19 Kamsteeg M, Rutherford T, Sapi E, Hanczaruk B, Shahabi S, Flick M, Brown D and Mor G: Phenoxodiol - an isoflavone analog - induces apoptosis in chemoresistant ovarian cancer cells. Oncogene 22: 2611-2620, 2003.

20 Gamble JR, Xia P, Hahn CN, Drew JJ, Drogemuller CJ, Brown $\mathrm{D}$ and Vadas MA: Phenoxodiol, an experimental anticancer drug, shows potent antiangiogenic properties in addition to its antitumour effects. Int J Cancer 118: 2412-2420, 2006.

21 Aguero MF, Facchinetti MM, Sheleg Z and Senderowicz AM: Phenoxodiol, a novel isoflavone, induces G1 arrest by specific loss in cyclin-dependent kinase 2 activity by p53-independent induction of p21WAF1/CIP1. Cancer Res 65: 3364-3373, 2005.

22 Constantinou AI and Husband A: Phenoxodiol (2H-1benzopyran-7-0,1,3-(4-hydroxyphenyl)), a novel isoflavone derivative, inhibits DNA topoisomerase II by stabilizing the cleavable complex. Anticancer Res 22: 2581-2585, 2002.

23 Alvero AB, O’Malley D, Brown D, Kelly G, Garg M, Chen W, Rutherford T and Mor G: Molecular mechanism of phenoxodiolinduced apoptosis in ovarian carcinoma cells. Cancer 106: 599608, 2006.

24 Matsuzaki S, Yoshino K,Ueda Y, Matsuzaki S, Kakuda M, Okazawa A, Egawa-Takata T, Kobayashi E and Kimura T: Potential targets for ovarian clear cell carcinoma: a review of updates and future perspectives. Cancer Cell Int 15: 117, 2015.

25 Ehrenschwender M, Bittner S, Seibold K and Wajant H: XIAPtargeting drugs re-sensitize PIK3CA-mutated colorectal cancer cells for death receptor-induced apoptosis. Cell Death Dis 5: e1570, 2014.

26 Kuo KT, Mao TL, Jones S, Veras E, Ayhan A, Wang TL, Glas R, Slamon D, Velculescu VE, Kuman RJ and Shih IeM: Frequent activating mutations of PIK3CA in ovarian clear cell carcinoma. Am J Pathol 174: 1597-1601, 2009. 